UNIVERSIDADE ESTADUAL PAULISTA

FACULDADE DE MEDICINA VETERINÁRIA E ZOOTECNIA

CAMPUS DE BOTUCATU

\title{
EFEITO DA IMUNIZAÇÃO ATIVA COM LÍQUIDO FOLICULAR BOVINO NA PROLIFICIDADE DE OVELHAS DA RAÇA IDEAL E MESTIÇAS SUFFOLK X IDEAL
}

JOÃO ELZEÁRIO CASTELO BRANCO IAPICHINI

Dissertação apresentada ao Curso de PósGraduação em Zootecnia - Área de Concentração: Nutrição e Produção Animal, como parte das exigências para obtenção do título de Mestre. 
UNIVERSIDADE ESTADUAL PAULISTA

FACULDADE DE MEDICINA VETERINÁRIA E ZOOTECNIA CAMPUS DE BOTUCATU

\title{
EFEITO DA IMUNIZAÇÃO ATIVA COM LÍQUIDO FOLICULAR BOVINO NA PROLIFICIDADE DE OVELHAS DA RAÇA IDEAL E MESTIÇAS SUFFOLK X IDEAL
}

\author{
JOÃO ELZEÁRIO CASTELO BRANCO IAPICHINI \\ Zootecnista
}

ORIENTADOR: Prof. Dr. ALEKSANDERS SPERS

\begin{abstract}
Dissertação apresentada ao Curso de PósGraduação em Zootecnia - Área de Concentração: Nutrição e Produção Animal, como parte das exigências para obtenção do título de Mestre.
\end{abstract}




\section{EFEITO DA IMUNIZAÇÃO ATIVA COM LÍQUIDO FOLICULAR BOVINO NA PROLIFICIDADE DE OVELHAS DA RAÇA IDEAL E MESTIÇAS SUFFOLK X IDEAL}

\section{Resumo}

O experimento desenvolveu-se no Posto Experimental de Ovinos e Caprinos do Instituto de Zootecnia de Itapetininga (SP), com o objetivo de avaliar o efeito da imunização ativa contra líquido folicular bovino (LFb) no índice de prolificidade de ovelhas manejadas em condiões de clima subtropical. $\mathrm{O}$ experimento foi inteiramente casualizado com esquema fatorial $2 \mathrm{x}$ 2, com 2 tratamentos: ovelhas imunizadas $(n=30)$, ovelhas controle $(n=30)$ e 2 graus de sangue: ovelhas Ideal e Mestiças (Ideal x Suffolk). Dos 30 animais tratados com LFb, 29 apresentaram respostas imunológicas ao tratamento. Não existiu efeito da imunização na taxa de fertilidade ou no comportamento estral das ovelhas $(\mathrm{P}>0,05)$. $\mathrm{O}$ índice médio de prolificidade das ovelhas imunizadas foi de 1,3 contra 1,0 do grupo controle $(\mathrm{P}<0,05)$. Não existiu efeito da raça no índice de prolificidade ( $P>0,05)$, mas houve efeito da imunização dentro de raça, para os animais mestiços $(\mathrm{P}<0,05)$. Essa diferença ocorreu devido ao maior número de parições gemelares das ovelhas imunizadas $(33 \%)$ em comparação as controle $(0 \%)$. Os resultados do presente estudo sugerem que o método de imunização contra LFb ofereçe uma alternativa para aumentar o número de nascimentos de ovelhas naturalmente pouco prolíficas criadas em condições de clima sub-tropical. 


\section{EFFECT OF ACTIVE IMMUNIZATION WITH BOVINE FOLLICULAR FLUID ON IDEAL AND SUFFOLK X IDEAL EWES PROLIFICITY}

\section{Summary}

The experiment was carried out in "Posto Experimental de Ovinos e Caprinos do Instituto de Zootecnia de Itapetininga (SP)" to study the effect of active immunization with bovine follicular fluid (bFF) on Ideal and Sufflolk x Ideal ewes prolificity rate reared in subtropical climatic conditions.

The experiment was entirely randomized, beirg 2 treatments: controle $(n=30)$ and immunized $(n=30)$ ewes and 2 breeds Ideal and Sufflolk x Ideal. From 30 treated ewes with bFF 29 (96,7\%) presented immunological response. Otherwise, immunization have no effect $(\mathrm{P}>.05)$ on fertility rate or oestral behavior. Average prolificity rate of immunized ewes $(1,3)$ was higher $(\mathrm{p}<.05)$ than controle $(1)$. Both breeds were similiar $(\mathrm{P}>.05)$ on prolificity rate, but occurried immunization effect $(\mathrm{P}<.05)$ in Suffolk $x$ Ideal ewes. This difference was because of higher gemelar parturition number of immunized ewes $(33 \%)$ against controle $(0 \%)$.

The results of present study suggest that immunization against bFF offers alternative method to increase the birth number of ewes which have low prolificity, reared in subtropical climatic conditions. 


\section{Introdução}

Nos animais domésticos, a taxa de ovulação, característica de cada espécie, é precisamente regulada por mecanismos endócrinos, autócrinos e parácrinos, comandados genéticamente. Na espécie ovina, o número de óvulos liberados a cada ciclo estral raramente ultrapassa a três (Hanrahan \& Quirke, 1985), sendo esse o fator determinante da prolificidade de uma determinada raça.

O aumento da prolificidade de ovelhas torna-se zootecnicamente interessante, por implicar num incremento, tanto na produção de lã como de carne.

Pesquisas prévias mostraram que é possível manipular a taxa de ovulação e o número de nascimentos, por meio de estímulo ou supressão de determinados hormônios gonadotróficos (FSH e LH) e esteróides (estradiol, androstenedione (Scaramuzzi \& Radford, 1983). Contudo, a utilização de vacinas contra esteróides apresentam riscos para a saúde humana, devido a presença de resíduos destes hormônios na carne destinada ao consumo humano.

Scaramuzzi \& Hoskinson (1984) e Oshea et al., (1993) relataram que é possível aumentar a taxa de ovulação e o número de nascimentos de ovelhas ativamente imunizadas contra líquido folicular parcialmente purificado ou contra inibina pura.

Cabe mencionar, entretanto, que esses trabalhos têm sido realizados com ovelhas de raças adaptadas às condições de clima temperado. 
O uso de líquido folicular bovino, livre de esteróides, como imunógeno elimina o inconveniente que representa à saúde humana a presença destes hormônios.

O objetivo do presente trabalho foi avaliar o aumento da prolificidade de ovelhas da raça Ideal e mestiças Ideal x Sufflolk, imunizadas contra líquido folicular bovino, desprovido de esteróides e criadas em condições de clima sub-tropical.

\section{Revisão de Literatura}

O estudo dos hormônios, que regulam o ciclo estral na espécie ovina, tem sido amplamente detalhado por diversos autores (Baird \& McNeilly, 1981; Goodman, 1988; Baird et al., 1991). A ovelha apresenta um ciclo estral de 17 dias, sendo que o dia do cio (dia zero), geralmente coincide com a descarga preovulatória de gonadotrofinas e a ovulação ocorre aproximadamente após 24 horas (Fabre-Nys \& Martin, 1991). Por sua vez, a luteólise acontece normalmente ao redor do $14^{\circ}$ ou $15^{\circ}$ dia do ciclo estral.

O ciclo ovariano nas ovelhas é regulado por inúmeras interrelações entre os hormônios do hipotálamo $(\mathrm{GnRH})$, da hipófise (LH e FSH), do folículo (estradiol e inibina), do corpo lúteo (progesterona e oxitocina) e do útero (prostaglandina $\mathrm{F}_{2} \alpha$ ). Essas interrelações controlam o ciclo estral, ovulação, formação do corpo lúteo e estabelecimento da prenhez. $\mathrm{O}$ ciclo estral é controlado inicialmente pelo hipotálamo $(\mathrm{GnRH})$, que estimula a secreção de gonadotrofinas da hipófise anterior. As gonadotrofinas 
estimulam o desenvolvimento folicular (McNeilly et al., 1991), conduzindo à ovulação e à formação do corpo lúteo. O desenvolvimento folicular é, por sua vez, regulado por um mecanismo "feedback" positivo e negativo, interligando o ovário ao sistema hipotálamo-hipofisário. (Baird et al., 1991; McNeilly et al., 1991). Após a ovulação, o corpo lúteo formado secreta progesterona, a qual permite o estabelecimento da prenhez e evita uma nova ovulação.

$\mathrm{Na}$ ausência de prenhez, a oxicitocina, liberada pelo corpo lúteo, estimula a liberação de prostaglandina $\mathrm{F}_{2} \propto$ uterina, que por sua vez provoca a luteólise, permitindo uma nova ovulação (Flint et al., 1989; Bazer et al., 1991).

$\mathrm{O}$ processo de crescimento e desenvolvimento folicular (foliculogênese) tem sido amplamente revisado por Hirshfield (1991) e Alvarez (1995). Na ovelha, a população de folículos destinados a ovular ou degenerar é formado no primeiro terço da vida fetal. Os primeiros folículos a deixarem o "pool" dos primordiais são aqueles da região mais interna do cortex ovariano (Smith et al., 1993). Os mecanismos responsáveis pela iniciação do crescimento não são conhecidos. Entretanto, evidência de estudos com animais hipofisectomizados, indica que os hormônios hipofisários (FSH e LH) não seriam requeridos (Alvarez, 1995).

Por outro lado, sabe-se que o crescimento dos folículos além de 2-5 mm de diâmetro, requerem FSH. Além disso, tais folículos também requerem LH para a produção de andrógenos, os quais servem de substrato, para a aromatização em estradiol. Folículos, no estádio de dependência às gonadotrofinas (> 2,0 mm de diâmetro), têm um alto requerimento por FSH, 
inclusive maior que o folículo ovulatório, característica essa que os distingue, e os torna mais vulneráveis à degeneração (McNeilly et al., 1992). Em consequência disso, o número de folículos maiores que 2,5 mm de diâmetro, em condições normais, é usualmente baixo, em média de 3 a 4 . $\mathrm{O}$ folículo préovulatório tem a capacidade de impedir o desenvolvimento dos outros folículos através do processo de recrutamento e seleção por meio de um mecanismo "feed-back" negativo do estradiol e da inibina, os quais reduzem o suprimento de FSH. Os folículos dependentes do FSH degeneram por causa das variações cíclicas desse hormônio que ocorrem durante o ciclo estral, com reduções na concentração aquém do limite crítico necessário para o crescimento normal. Mecanismos parácrinos e autócrinos realçam a sensibilidade desses folículos ao FSH e resulta na expressão de receptores para LH nas células da granulosa (Alvarez, 1995). Desta forma, o LH pode estimular a atividade aromatase, e devido a isso, constituir um substituto do FSH neste estádio. Tais sensibilidades transformam o folículo gonadotrofodependente em folículo pré-ovulatório (Scaramuzzi \& Radford, 1983) .

A transformação do folículo gonadotrofo-dependente em um folículo capaz de ovular, requer uma baixa, porém crítica concentração de FSH para induzir a maturação final das células da granulosa (Henderson et al., 1988). Este nível crítico de FSH não é conhecido, sendo provável a existência de uma variação individual entre animais e inclusive nos diferentes ciclos estrais de um mesmo animal.

Os folículos pré-ovulatórios possuem um grande número de receptores para LH nas células da granulosa (Webb \& England, 1982); e, 
consequentemente, estas células começam a responder ao LH tanto quanto ao FSH e, devido a isto, à atividade aromatase.

O aumento da secreção de estradiol e inibina reduz o FSH a níveis mínimos, insuficientes aos requeridos pelos folículos de menor tamanho. Por outro lado, a resposta ao FSH, medida pela produção de cAMP, aumenta 2 a 10 vezes na medida em que aumenta o diâmetro dos folículos de 2,5 $\mathrm{mm}$ para 6,0 $\mathrm{mm}$ (Henderson et al., 1987). Consequentemente, durante a fase folicular final, os folículos são sustentados até a ovulação, a despeito da baixa concentração de FSH na circulação. Em termos de produção de cAMP, as células da granulosa respondem 10 vezes mais ao LH do que ao FSH, por isso possibilitam ao LH agir como um substituto do FSH nessas células.

Outros reguladores locais, tais como as somatomedinas (IGF I e II), fator transformador do crescimento (TGF) e fator do crescimento dos fibroblastos (FGF), podem igualmente responder às gonadotrofinas (Hsueh et al., 1989).

De forma semelhante, outros fatores locais como a inibina (Campbell et al., 1992), o fator de crescimento epidermal (EGF), ou o TGF $\propto$, podem inibir a resposta " in vivo" às gonadotrofinas. A ativina, entretanto, tem sido reportada por ter no folículo tanto efeitos inibitórios (Hillier et al., 1991a e 1991b), como estimulatórios (Findlay et al., 1990; Findlay, 1993) no crescimento folicular.

$\mathrm{Na}$ fase folicular normal, o folículo pré-ovulatório é exposto a altos níveis de $\mathrm{LH}$, enquanto que a concentração de FSH é reduzida e insuficiente para manter o crescimento dos folículos gonadotrofo- 
dependentes. Sob a estimulação de LH, os folículos pré-ovulatórios aumentam de tamanho, levando a uma maior secreção de estradiol, a qual induz uma grande liberação de GnRH do hipotálamo e, consequentemente, do LH hipofisário (Caraty et al., 1989). Desse modo essa descarga provoca a ovulação aproximadamente 24 horas após.

Os folículos ovulatórios também se desenvolvem durante a fase luteínica (Brand \& De Jong, 1973; Scaramuzzi \& Hoskinson, 1984). Assumese que o mecanismo de transformação do folículo, dominante neste período, é similar ao observado durante a fase folicular. Entretanto, há importantes diferenças entre as fases foliculares e luteínicas do ciclo estral que podem influenciar o desenvolvimento folicular. Durante a fase luteínica, o alto nível de progesterona reduz a frequência dos pulsos de LH para valores que ficam muito aquém dos necessários para manter o folículo ovulatório. Estes folículos eventualmente sofrem atresia quando a ação do " feedback “ combinado de inibina e estradiol reduz o FSH abaixo da concentração mínima requerida. Alternativamente, tanto os mecanismos autócrinos como os parácrinos que protegem os folículos ovulatórios da atresia, ao reduzir à necessidade de FSH, podem somente oferecer uma proteção a curto prazo. $\mathrm{Na}$ ausência de uma descarga de LH, a atresia eventualmente ocorreria quando estes mecanismos estão ausentes.

A queda na concentração de FSH, abaixo dos limites para desenvolvimento dos folículos gonadotrofo-dependentes, durante a fase folicular, causa a atresia de quase todos os folículos, e nenhum prossegue até o estádio ovulatório (McNatty, 1982). A completa atresia de todos os folículos gonadotrofo-dependentes é promovida pelos efeitos tóxicos de altos 
níveis de LH liberado durante a descarga pré-ovulatória. A reposição de folículos ovulatórios obtidos do "pool" dos folículos secundários não são evidentes até 2 a 3 dias do novo ciclo estral (Baird \& McNeilly, 1981).

O modelo funcional descrito para a foliculogênese descreve o crescimento e desenvolvimento do folículo ovulatório, mas não explica o mecanismo que controla o número de folículos ovulatórios, presentes em qualquer momento. Nas ovelhas mono-ovulatórias, um único folículo ovulatório desenvolve-se pelo mecanismo descrito anteriormente. Há somente um folículo ovulatório, porque a viabilidade do folículo gonadotrofodependente é severamente restrito pelo aumento do requerimento de FSH, e pela atividade "feedback" do folículo ovulatório. Estes fatores, junto com o número limitado de folículos secundários, restringe o número de folículos ovulatórios a um. Os folículos gonadotrofo-dependentes requerem um aumento de FSH para metabolizar a quantidade total de andrógenos produzidos pela teca interna. A incapacidade das tecas para efetuar o metabolismo dos andrógenos, em estrógenos, conduz à alta concentração de andrógenos nas mesmas (Fortune, 1986). Compostos como a dihidrotestosterona podem inibir a atividade aromatase e estar direta ou indiretamente associados com a atresia folicular. $\mathrm{O}$ mecanismo da atresia não é conhecido, mas pode envolver a estimulação hormonal trófica inapropriada de esteróides e agentes tais como as prostaglandinas, EGF e/ou TGF, atuando localmente (Lobb \& Dorrington, 1992; Murray et al., 1993). A sensibilidade do hipotálamo e da hipófise anterior ao estradiol e à inibina, secretados pelos folículos ovulatórios, também afetam a viabilidade dos folículos gonadotrodependentes, influenciando a concentração de FSH no plasma, em resposta ao 
" feedback" negativo dos hormônios ovarianos. Uma rápida queda na concentração de FSH no plasma, está associada com um curto período de viabilidade dos folículos gonadotrofo-dependentes e favorece $o$ desenvolvimento do folículo ovulatório único (Henderson et al., 1988).

O número dos folículos ovulatórios é, deste modo, determinado por vários fatores agindo em acordo. São eles: o número de folículos secundários disponíveis para transformação em folículo gonadotrofodependente; a viabilidade dos folículos gonadotrofo-dependentes em função do requerimento individual de FSH e, finalmente, a sensibilidade do eixo hipotálamo- hipofisário ao efeito inibitório do estradiol e da inibina na secreção de FSH.

Em ovelhas multi-ovulatórias, dois ou mais folículos ovulatórios estão presentes e dois mecanismos são propostos para explicar esse fenômeno. No primeiro, a ovulação acontece quando a viabilidade dos folículos gonadotrofo-dependentes é aumentada pela ampliação do número de folículos que estão "no tempo certo e no momento certo" (Hirshfield, 1991; Scaramuzzi \& Radford, 1983). Isso pode ser definido como o período de tempo em que os folículos adquirem maior sensibilidade ao FSH. No segundo mecanismo, a ovulação múltipla pode ser determinada pelo aumento do número de folículos secundários, disponíveis para iniciar o desenvolvimento. Isto pode acontecer pelo aumento do tamanho do "pool" de pequenos folículos antrais, e consequentemente, o potencial para mais folículos desenvolverem, em folículos gonadotrofo-dependentes. 
A administração de FSH e moléculas FSH-Like (por exemplo, gonadotrofina do soro de égua prenha ou da gonadotrofina humana na menopausa), aumenta a taxa de ovulação ao impedir a atresia dos folículos gonadotrofo-dependentes, aumentando o número de folículos secundários, entrando na população de folículos gonadotrofo-dependentes (Hay \& Moor, 1975). Da mesma forma, a administração de LH e LH-like (por exemplo gonadotrofina coriônica humana) não aumenta a taxa de ovulação (Scaramuzzi \& Radford, 1983). Uma associação entre pulsos de LH na fase luteínica do ciclo estral e a taxa de ovulação da ovulação seguinte têm sido relatada (Thomas et al., 1984). Entretanto, tentativas de aumentar a taxa de ovulação pelo incremento da frequiência de pulsos de LH, durante a fase luteínica, não têm tido sucesso (McNatty et al., 1981). O consenso é que LH exógeno não aumenta a taxa de ovulação.

A imunização contra estrógenos que são inibidores "fedback" negativo de LH e FSH, aumenta marcadamente a secreção de gonadotrofinas (Scaramuzzi \& Hoskinson, 1984). Neste caso, o aumento na taxa de ovulação pode ser atribuido à alta concentração de FSH em animais imunizados. A alta concentração de LH, e em particular o aumento da amplitude de pulsos, que resulta da imunização contra estrógenos, poderia aumentar a taxa de atresia (McNeilly et al., 1991), mas este efeito provavelmente é evitado pelos níveis elevados de FSH (Picton et al., 1990; McNatty et al., 1992).

Diferentemente da imunização contra estrógenos, a imunização contra androstenedione aumenta a secreção de LH, mas tem pequeno ou nenhum efeito na concentração de FSH (McNatty et al., 1988; Campbell et al., 1991). Os ovários de animais imunizados contra androstenedione usualmente 
contém dois folículos ovulatórios e isto resulta na duplicação da secreção de inibina pelo ovário (Campbell et al., 1990a). Entretanto, a secreção de estradiol não é aumentada, provavelmente devido a uma relativa falta de androstenedione para aromatização (Campbell et al., 1990b).

A imunização contra inibina ou líquido folicular bovino parcialmente purificado, também aumenta a taxa de ovulação (Henderson et al., 1984; Forage et al., 1987; Price et al., 1987: O’ Shea et al., 1989 e 1993). Os efeitos da imunização contra inibina, ou vários fragmentos da molécula de inibina, podem ser avaliados pela imunoneutralização da atividade biológica da inibina endógena, resultando em aumento dos níveis de FSH (O' Shea et al., 1989). Entretanto, com o tempo, os níveis de FSH são atenuados pelo incremento da secreção de estradiol, provenientes dos folículos gonadotrofodependentes e dos folículos ovulatórios, produzidos em resposta ao aumento na concentração de FSH.

O líquido folicular bovino possui outras substâncias como a ativina, que poderiam atuar de forma antagônica à inibina, entretanto, estudos “ in vitro" mostram que a ação da inibina é preferencial.

\section{Material e Métodos}

\section{Local}

O experimento foi conduzido no Posto Experimental de Ovinos e Caprinos do Instituto de Zootecnica, localizado na Estrada Velha 
Tatuí/Itapetininga - Bairro Capão Alto, no Município de Itapetininga (SP). A região localiza-se na latitude $23^{\circ} 35^{\prime}$ Sul e longitude $48^{\circ} 02^{\prime}$ 'Oeste, em solo classificado como latossolo vermelho escuro orto, clima temperado subtropical de tipo savana, com precipitação pluviométrica anual média de 1.150 mm e temperatura média de $18^{\circ} \mathrm{C}$, sendo a máxima de $23^{\circ} \mathrm{C}$ e a mínima de $8,3^{\circ} \mathrm{C}$ (Prucoli, 1981).

\section{Animais}

Foram utilizadas 60 ovelhas primíparas das raças Ideal $(n=30)$ e Mestiças Suffollk x Ideal $(\mathrm{n}=30)$, com idade média de 2 anos, mantidas sob pastejo contínuo, em pastagens de Digitaria decumbens Stent e Brachiaria decumbens, com suplementação alimentar no período de inverno consistindo de volumoso (capim Napier e Cana) e $0,300 \mathrm{~kg}$ de rolão de milho por animal. A mineralização foi ministrada "ad libitum" durante o experimento em cochos distribuido nas pastagens.

O manejo profilático dos animais incluiu a vermifugação periódica dos animais em função da existência de sintomatologia clínica de verminose e do resultado de exame de fezes, bem como vacinação contra a febre aftosa.

Obtenção e preparo do Líquido Folicular Bovino (LFb)

Durante um período de 4 meses, foram colhidos ovários provenientes de 500 fêmeas, tanto vacas como novilhas, abatidas no 
frigorífico Anglo, localizado na cidade de Barretos (SP). A cada colheita, todos os folículos visíveis nos ovários, exceto os considerados maiores que 22 $\mathrm{mm}$ de diâmetro, foram puncionados utilizando-se agulha 25 x $08 \mathrm{~mm}$ acoplada a uma seringa de $10 \mathrm{ml}$. O intervalo entre o sacrifício do animal e a aspiração do líquido foi de aproximadamente 1 hora, tempo em que os ovários foram mantidos no gelo. No total, $400 \mathrm{ml}$ de $\mathrm{LFb}$ recuperados de 5 séries de coletas foram congelados a $18^{\circ} \mathrm{C}$.

Com a finalidade de remoção dos hormônios esteróides, o material colhido foi descongelado e manipulado no laboratório do Departamento de Reprodução da FCAVJ - UNESP - Jaboticabal, SP, da seguinte forma:

$\mathrm{O} \mathrm{LFb}$ foi adicionado de $50 \mathrm{mg}$ de carvão ativado (Sigma Chemical, St. Louis, M O) para cada ml, e mantido em agitação moderada durante 45 minutos a $4^{\circ} \mathrm{C}$. Em seguida o carvão foi eliminado por centrifugação (13.000 rpm durante 1 hora a $4^{\circ} \mathrm{C}$ ), antes de ser estocado em frascos estéreis de $10 \mathrm{ml}$ e congelado a $-18^{\circ} \mathrm{C}$ para posterior utilização.

As dosagens plasmáticas dos hormônios esteróides foram realizadas pelo método de radioimunoensaio (RIE), utilizando a técnica convencional do laboratório de Fisiologia da Reprodução do Departamento de Fisiologia da Faculdade de Medicina, USP, Ribeirão Preto, SP (Alvarez, 1995).

O processamento do $\mathrm{LFb}$ com carvão ativado permitiu eliminar mais de $99 \%$ do conteúdo de esteróides (E2-17ß e P4), inicialmente presentes no LFb (Tabela 1) 
Tabela 1. Concentração de esteróides $\left(\mathrm{P}_{4}\right.$ e $\left.\mathrm{E}_{2}-17 \beta\right)$ no $\mathrm{LFb}$ antes e depois do tratamento com carvão ativado.

\begin{tabular}{lcc}
\hline Hormônio & LFb & LFb + carvão \\
\hline E2 (pg/ml) & 3322.04 & 4.70 \\
P4 (ng/ml) & 35.15 & 0.15 \\
\hline
\end{tabular}

A preparação final do imunógeno foi obtida da seguinte forma: $20 \mathrm{ml}$ do líquido folicular tratado foram misturados com $13 \mathrm{ml}$ de adjuvante de Freunds completo (Sigma chemical St. Louis, MO) e 3,2 $\mathrm{ml}$ de tween 80 (Sigma chemical St. Louis, MO) em 23,8 ml de solução salina (PBS) .

Protocolos de imunização

A primeira imunização ocorreu no mês de abril de 1994. Cada animal do grupo imunizado recebeu 2,5 $\mathrm{ml}$ do imunógeno contendo o $\mathrm{LFb}$, enquanto que o grupo controle recebeu unicamente o preparado desprovido do LFb. A imunização foi realizada por via sub-cutânea com 4 injeções distribuídas no dorso do animal.

Trinta dias após a primeira inoculação, foi aplicada uma injeção de reforço, substituindo o adjuvante completo de Freunds pelo incompleto.

Quinze após a primeira imunização iniciou-se o acasalamento das ovelhas. ...Prévia detecção do cio das ovelhas feita através de rufiões marcadores sendo que a estação de monta transcorreu de $1^{\circ}$ de maio a 30 de junho de 1994. 
Protocolo Experimental

As ovelhas foram distríbuidas ao acaso em 2 tratamentos de 30 ovelhas, da seguinte forma: Tratamento 1 (ovelhas imunizadas) e Tratamento 2 (ovelhas não imunizadas).

O experimento foi inteiramente casualizado com dois tratamentos (ovelhas imunizadas e não imunizadas) sendo: 02 doses de líquido folicular $\left(0\right.$ e $2,5 \mathrm{ml} \mathrm{animal}^{-1}$ ) e 02 graus de sangue (Ideal e mestiças Ideal x Suffolk). Assim, os 4 tratamentos foram: I 0, I 2,5, M0 e M 2,5 com 15 animais cada.

\section{Colheita de sangue}

Amostras de sangue da veia jugular foram retiradas, a partir da primeira imunização, utilizando-se tubos vacutainer estéreis. Após repouso do sangue à temperatura ambiente, o material foi centrifugado $(3.000 \mathrm{rpm} / 10$ min.) e posteriormente estocado e congelado para realização dos testes de imunodifusão.

\section{Teste de Imunodifusão}

A identificação dos anticorpos presentes no anti-soro foi realizada pela técnica de difusão dupla em ágar (técnica de Ouchterlony). Resumidamente, após preparação de placas de vidro em ágar de azida de sódio, $20 \mu \mathrm{l}$ de $\mathrm{LFb}$ diluído (concentração final $1 \mathrm{mg} / \mathrm{ml}$ ) foram colocados no poço central e 20 ul de anti-soro ovino em diluições seriadas (original, 1/2, 1/4, 
$1 / 8,1 / 16 \mathrm{e}^{1 / 32}$ ), nos orifícios periféricos. As linhas de precipitação, formadas ao nível do ponto de equivalência entre o antígeno e o anticorpo, foram observadas quarenta e oito horas após a incubação a $4^{\circ} \mathrm{C}$ em atmosfera úmida. Em seguida, as proteínas precipitadas foram coradas pela imersão das placas numa solução de Negro Amido 0,5\% durante 10 minutos.

Análise estatística dos dados

Os dados relativos ao efeito do tratamento no índice de prolificidade das ovelhas foram comparados através da análise de variância (ANOVA), enquanto que a frequiência dos animais que responderam ao tratamento, com mais de um nascimento, foram analisados pelo teste exato de Fisher, utilizando o Sistema Computacional Statistica, Stat Soft, Inc. 1993, versão 4.5 .

\section{Resultados e Discussão}

\section{a) Respostas da imunização com LFb}

A imunização de ovelhas com $\mathrm{LFb}$ resultou no desenvolvimento de linhas características de precipitação antígeno-anticorpo em 29 das 30 ovelhas imunizadas. A ovelha, na qual não foi observada nenhuma reação de precipitação no teste de imunodifusão, teve parto simples. Foram evidenciadas várias linhas na reação de precipitação 30 dias após a imunização inicial (Figura 1). Essa resposta imunológica pode ser considerada satisfatória em comparação aos resultados de outros estudos de 
imunização, onde utilizou-se o mesmo tipo de imunógeno. Segundo Alvarez (1995), existe uma grande variação na resposta à imunização entre ovelhas e dentro de ovelhas.

Não foi testado o tipo de proteína que causou a reação imunólógica no teste de imunodifusão. É conhecido que o LFb contém pelo menos 40 proteínas séricas de elevado peso molecular (Andersen et al., 1976) e algumas outras proteínas específicas do folículo, pertencente a família da inibina, as quais apresentam uma ação biológica no controle do crescimento folicular e na liberação de FSH hipofisário (Alvarez, 1995).

Estudos prévios, mostraram que a inibina presente no $\mathrm{LFb}$ (peso molecular $32 \mathrm{kD}$ ) provoca uma reação biológica em ovelhas, quando associada a um adjuvante (Alvarez, 1995). Entretanto, na falta de inibina purificada, para servir como antígeno na reação de imunodifusão no presente experimento, não foi possível confirmar a presença de anticorpos contra esta molécula. Em todo caso, é relevante mencionar que existem trabalhos mostrando que além da inibina, outras substâncias não esteroidais presentes no $\mathrm{LFb}$, podem ser responsáveis por modificações no crescimento folicular (Campbell et al., 1991).

\section{b) Avaliação do índice de prolificidade}

A Tabela 2 mostra a distribuição das ovelhas expostas a cobertura, durante o período experimental. 
Observa-se que $66,6 \%$ das ovelhas controle foram cobertas contra $73,3 \%$ das ovelhas imunizadas. Não existiu efeito significativo dos animais imunizados em comparação ao controle $(\mathrm{P}>0,05)$. $\mathrm{O}$ número de animais não acasalados pode ser considerado normal, tendo em vista a restrição imposta no período da estação de monta (dois meses). Em condições normais, na estação de monta (cinco meses), é esperado que aproximadamente mais de $90 \%$ dos animais expostos sejam cobertos (Cardellino et al., 1991).

Relatos prévios tem mostrado que a injeção com $\mathrm{LFb}$ provoca atraso no cio e ovulação em ovelhas (Wallace \& McNeilly, 1985), bem como no aparecimento da primeira onda de crescimento folicular em bovinos (Turzillo \& Fortune, 1990).

Considerando estes resultados, a imunização contra $\mathrm{LFb}$ poderia ter um efeito no sentido de adiantar e/ou tornar mais evidente a manifestação do cio. Em animais tratados com FSH, por exemplo, a superovulação provoca um avanço de aproximadamente vinte e quatro horas na manifestação do cio, em comparação aos animais não superovulados (Alvarez, 1985).

Esse efeito seria provocado pela elevada concentração de estrógenos no sangue em consequência do maior número de folículos pré ovulatórios. Provavelmente, o estímulo ovariano das ovelhas imunizadas, no presente estudo, não foi suficientemente intenso para provocar mudanças significativas no comportamento estral.

Quando considerado o número de ovelhas paridas, em relação ao número de ovelhas expostas (taxa de fertilidade), observou-se que não existiu diferença entre o grupo controle e imunizado (Tabela 3), porém foi observado 
uma diferença siginificativa na taxa de fertilidade entre a raça Ideal e Mestiças ( $\mathrm{P}<0,01)$ (Tabela 4). A análise dos dados, dentro de cada raça não mostrou efeito dos tratamentos na fertilidade ( Tabelas 5 e 6 ).

A taxa de fertilidade relativamente baixa da raça Ideal pode sugerir que a mesma possue uma atividade sexual mais estacional que as mestiças Ideal x Sufflolk. Entretanto, resultados prévios com ovelhas manejadas em condições semelhantes, mostraram índices de fertilidade menores que $40 \%$ nos meses de maio a junho para os animais da raça Ideal e mestiças (Roda et al., 1993).

No geral, das 29 ovelhas que levaram a termo a gestação, nasceram 34 cordeiros (as). Das ovelhas imunizadas, $33 \%$ apresentaram parições gemelares contra $0 \%$ das controle $(\mathrm{P}<0,05)$. $\mathrm{O}$ índice de prolificidade, definido como o número de cordeiros nascidos em relação ao número de ovelhas paridas, foi significativamente maior $(\mathrm{P}<0,05)$ nas ovelhas imunizadas (média de 1,3), em comparação com as controle (média de 1,0) (Quadro 1), podendo isto ser explicado pela maior proporção de parições gemelares das ovelhas imunizadas (Tabela 7).

O pequeno número de parições da raça ideal não permitiu fazer uma comparação consistente entre raças. Os resultados mostraram que a imunização contra $\mathrm{LFb}$ provocou um aumento na prolificidade, ou seja: 1/3 das ovelhas Ideal tiveram gestações gemelares contra 0/4 nas ovelhas controle (Tabela 8). Por sua vez, as ovelhas mestiças, imunizadas contra LFb, tiveram uma prolificidade maior $(4 / 11)$ que o grupo controle $(0 / 11)(\mathrm{P}<0,05)$ (Tabela 9). 


\section{Conclusões}

1. A imunização ativa contra $\mathrm{LFb}$ não alterou os padrões reprodutivos normais relativos à taxa de fertilidade e manifestação do cio.

2. A imunização ativa contra LFb aumentou em $33 \%$ a taxa de nascimentos gemelares em comparação ao grupo controle

3. A resposta à imunização é imprescindível visto que um grande número de animais não modifica seu índice natural de prolificidade, apesar da presença de anticorpos anti-LFb.

\section{Implicações}

Os resultados encontrados no presente estudo oferecem uma alternativa para aumentar a eficiência reprodutiva de ovelhas normalmente pouca prolíficas, sendo o método exeqüível a nível de campo e de baixo custo.

\section{Referências Bibliográficas}

ALVAREZ, R. H. Contribution à l' étude de la production et de la congelation d' embryons chez les bovins. Maisons-Alfort: École Nationale Vétérinaire d'Alfort, 1985. 102 p. Dissertação (Maitre es Sciences Vétérinaires) - École Nationale Vétérinaire d' Alfort, France. 
ALVAREZ, R. H. Efeito da imunização passiva contra o líquido folicular bovino na taxa de ovulação e na produção de embriões de vacas superovuladas e não superovuladas. Tese apresentada a UNESP, Jaboticabal, para obtenção do título de Doutor em Zootecnia, 1995.

ANDERSEN, M. M., KROLL, J., BYSKOV, A. G. \& FABER, M. J. Protein composition in the fluid of individual bovine follicles. J. Reprod. Fertil. 48: p. 109-118, 1976

BAIRD, D. T. \& McNEILLY, A. S. Gonadotrophin control of follicular development and function during the oestrus cycle of the ewe. J. Reprod. Fertil. (Suppl.) 30: p. 119-133, 1981.

BAIRD, D. T., CAMPBELl, B. K., MANN, G. E. \& McNEILLY, A. S. Inhibin and oestradiol in the control of FSH secretion in the sheep. $J$. Reprod. Fertil. (Suppl.) 43 : p. 125-138, 1991.

BAZER, F. W., THATCHER, W. W., HANSEN, P. J., MIRANDO, M. A., OTT, T. L. \& PLANTE, C. Physiological mechanisms of pregnancy recognition in ruminants. J. Reprod. Fertil. (Suppl.) 43: p. 39-47, 1991.

BRAND, A. \& DE JONG, W. H. R. Qualitative and quantitative micromorphological investigations of the tertiary follicle population during the oestrus cycle in sheep. J. Reprod. Fertil. 33: p. 431-439, 1973.

CAMPBELL, B. K., BAIRD, D. T., McNEILLY, A. S., SCARAMUZZI, R. J. Ovarian secretion rates and peripheral concentrations of inhibin in normal and androstenedione-immune ewes with an autotransplanted ovary. $J$. Endocrinol. 127, p. 285-296, 1990a. 
CAMPBELL, B. K., SCARAMUZZI, R. J., DOWNING, J. A. \& EVANS, G. Steroid secretion rates and plasma binding activity in ewes with an ovarian autotransplant actively immunized against androstenedione. J. Reprod. Fertil. 89, p. 485-496, 1990b.

CAMPBELL, B. K., SCARAMUZZI, R. J., EVANS, G. \& DOWNING, J. A. Increased ovulation rate in androstenedione-immune ewes is not due to elevated plasma concentrations of FSH. J. Reprod. Fertil. 91, p. 655-666, 1991.

CAMPBELL, B. K., TSONIS, C. G., GORDON, B.M. \& SCARAMUZZI, R. J. Ovarian arterial infusion of recombinant human inhibin and bovine follicular fluid (bFF) inhibits ovarian oestradiol secretion. J. Reprod. Fertil. Abstract Series 9, p. 20, 1992.

CARATY, A., LOCATELLI, A., MARTIN, G. B. Biphasic secretion of gonadotrophin-releasing hormone $(\mathrm{GnRH})$ in ovariectomized ewes injected with oestradiol. J. Endocrinol. 123, p. 375-382, 1989.

CARDELlinO, R. C., JAMES, J. W., AZZARINE \& PONZONI, R. W. Desempeño reproductivo, producción de lana y peso vivo en hembras Corriedade, Ideal y Merino del Uruguai. Producción Ovina, 3 (1-2), p. 7180, 1991.

FABRE-NYS, C. \& MARTIN, G. B. Hormonal control of proceptive and respective sexual behaviour and the preovulatory LH surge in the ewe: reassessment of the respective roles of estradiol, testosterone and progesterone. Horm. Behav. 25, p. 295-312, 1991. 
FINDLAY, J. K., XIAO, S. \& SHUKOWSKI, L. Role of inhibin-related peptides as intragonal regulators. Reprod. Fertil. Dev. 2, p. 205-218, 1990.

FINDLAY, J. K. An update on the roles of inhibin, activin and follistatin as local regulators of folliculogenesis. Biol. Reprod. 48, p. 15-23, 1993.

FLINT, A. P. F., SHELDRICK, E. L., JONES, D. C. S. \& AULETTA, F. J. Adaptations to pregnancy in the interations between luteal oxytocin and the uterus in ruminants. J. Reprod. Fertil. (Suppl.) 37, p. 195-204, 1989.

FORAGE, R. G., BROWN, R. W., OLIVER, K. G., ATRACHE, B. T., DEVINE, P. L., HUDSON, G. C., GOSS, N. H., BERTRAM, K. C., TOLSTOSHEV, P., ROBERTSON, D. M., DE KRETSER, D. M., DOUGHTON, D., BURGER, H. G. \& FINDLAY, J. K. Immunization against inhibin subunit produced by recombinant DNA technology results in increased ovulation rate in sheep. J. Endocrinol. 114, R1-R4, 1987.

FORTUNE, J. E. Bovine theca and granulosa cells interact to promote androgen production. Biol. Reprod. 35, p. 292-299, 1986.

GOODMAN, R. L. Neuroendocrine control of the ovine oestrus cycle. In ' The Physiology of Reproduction. (Eds E. Knobil \& J. Neill.) p. 1929-1969. (Raven Press Ltd: New York.), 1988.

HANRAHAN, J. P. \& QUIRKE, J. F. Contribution of variation in ovulation rate and embryo survival to within breed variation in litter size. In "Genetics of Reproduction in Sheep". (Eds R. B. Land \& D. W. Robinson.) p. 193-201. (Butterworths: London.), 1985. 
HAY, M. F. \& MOOR, R. M. Functional and structural relationships in the Graafian follicle population of the sheep ovary. J. Reprod. Fertil. 45, p. 583-593, 1975.

HENDERSON, K. M., FRANCHIMONT, P., LECOMTE-YERNA, M. J., HUDSON, N. \& BALL, K. Increase in ovulation rate after active immunization of sheep with inhibin partially purified from bovine follicular fluid. J. Endocrinol. 102, p. 305-309, 1984.

HENDERSON, K. M., McNATTY, K. P., O'KEEFE, L. E., LUN, S., HEATH, D. A. \& PRISK, M. D. Differences in gonadotropin-stimulated cyclic AMP production by granulosa cells from Booroola x Merino ewes which are homozygous, heterozygous or non-carriers of a fecundity gene influencing their ovulation rate. J. Reprod. Fertil. 81, p. 395-402, 1987.

HENDERSON, K. M., SAVAGE, L. C., Ellen, R. L., BALL, K. \& McNATTY, K. P. Consequences of increasing or decreasing plasma FSH concentrations during the preovulatory period in Romney ewes. J. Reprod. Fertil. 84, p. 187-196, 1988.

HILLIER, S. G., YONG, E. L., ILLINGWORTH, P. J., BAIRD, D. T., SCHWALL, R. H. \& MASON, A. J. Effect of recombinant inhibin on androgen synthesis in cultured human thecal cells. Mol. Cell. Endocr. 75, R-1-R6, 1991a.

HILliER, S. G., YONG, E. L., ILlingWORTH, P.J., BAIRD, D. T., SCHWALL, R.H. \& MASON, A. J. Effect of recombinant activin on androgen synthesis in cultured human thecal cells. J. Clin. Endocrinol. Metab. 72, p. 1206-1211, 1991b. 
HIRSHFIELD, A. N. Development of follicles in the mammalian ovary. Int. Rev. Cytol. 124, p. 43-101, 1991.

HSUEH, A. J. W., BICSAK, T. A., JIA, X. C., DAHL, K. D., FAUSER, B. C. J. M., GALWAY, A. B., CZEKALA, N., PAVLOU, S. N., PAPKOFF, H., KEENE, J. \& BOIME, I. Granulosa cells as hormone in reproduction. Recent Prog. Horm. Res. 45, p. 209-277, 1989.

LOBB, D. K. \& DORRINGTON, J. Intraovarian regulation of follicular development. Anim. Reprod. Sci. 28, p. 343-354, 1992.

McNATTY, K.P., GIBB, M., DOBSON, C. \& THURLEY, D.C. Evidence that changes in luteinizing secretion regulate the growth of the preovulatory follicle en the ewe. J.Endocrinol. 90, p. 375-389, 1981.

McNATTY, K. P. Ovarian follicular development from the onset of luteal regression in humans and sheep. In "Follicular Maturation and Ovulation". (Eds R. Rolland, E. V. Van Hall, S. G. Hillier, K. P. McNatty \& J. Schoemaker.) p. 1-18 (Excerpta Medica Press: Amsterdam.), 1982

McNATTY, K. P., HUDSON, N. L., GIBB, M. \& COLlinS, F. L. The plasma concentrations of FSH, LH, and progesterone in sheep immunized against an androstenedione-protein conjugate. J. Reprod. Fertil. 82, p. 6369, 1988.

McNATTY, K. P., SMITH, P., HUDSON, N. L., HEATH, D. A., LUN, S., \& O, W. S. Follicular development and steroidogenesis. In "Local Regulation of Ovarian Function" . (Eds N. O. Sjoberg, L. Hamberger, P. O. Jansen, C. Owman and H. I. J. Coelingh.) P. 21-28. (The Pathenon Publishing Group Carforth: Lanacs. UK.), 1992. 
McNEILly, A. S., PICTON, H. M., CAMPBELL, B. K. \& BAIRD, D. T. Gonadotrophic control of follicle growth in the ewe. J. Reprod. Fertil. (Suppl.) 43, p. 177-186, 1991.

McNEILLY, A. S., CROW, A. S., BROOKS, J. \& EVANS, G. Luteinizing hormone pulses, follicle stimulating hormone and the control of follicle selection. J. Reprod. Fertil. (Suppl.) 45, p. 5-19, 1992.

MURRAY, J. F., DOWING, J. A., EVANS, G., FINDLAY, J. K. \& SCARAMUZZI, R. J. Epidermal growth factor acts directly on the ovary in vivo to inhibin oestradiol-17 $\beta$ and inhibin secretion and enhance progesterone secretion. J. Endocrinol, 137, p. 253-264, 1993.

O'SHEA, R., BINDON, B. M., HILLARD, M.A., PIPER, L. R., FINDLAY, J. K. \& MYAMOTO, K. Increase in ovulation rate in Merino ewes after active immunization with inhibin preparations obtained by immunoaffinity chromatography. Reprod. Fertil. Dev. 1, p. 347-355, 1989.

O'SHEA, T., BINDON, B. M., FORAGE, R.G., FINDLAY, J. K. \& TSONIS C. G. Active immunization of Merino ewe lambs with recombinant bovine alpha inhibin advances puberty and increases ovulation rate. Reprod. Fertil. Dev. 5, p. 173-180, 1993.

PICTON, H. M., TSONIS, C. G. \& McNEILLY, A. S. The antagonistic effect of exogenous LH pulses on FSH-stimulated preovulatory follicle growth in ewes chronically treated with gonadotrophin-releasing hormone agonist. $J$. endocrinol, 127, p. 273-283, 1990. 
PRICE, C. A., MORRIS, B. A., O' SHEA, T. \& WEBB, R. Active immunization of cattle against partially purified follicular fluid from shepp. J. Reprod. Fertil. 81, p. 161-168, 1987.

PRUCOLI, J. O., RODA, D. S., SANTOS, L. E. Crescimento de caprinos das raças Anglo-Nubian, Togemburg e Moxotó do nascimento a um ano de idade, do Posto de Ovinos e Caprinos de Itapetininga (SP). B. Indústr. Anim., Nova Odessa, SP, 38(2) p. 205-217, 1981.

RODA, D. S., SANTOS, L. E., CUNHA, E. A., BIANCHINI, D. \& FEITOZA, A. S. L. Desempenho de ovinos em sitema de acasalamento a cada oito meses. B. Indústr. Anim., Nova Odessa, SP. 50 (1): p. 49-54, 1993.

SCARAMUZZI, R. J. \& RADFORD, H. M. Factors regulating ovulation rate in the ewe. J. Reprod. Fertil. 69, p. 353-367, 1983.

SCARAMUZZI, R. J. \& HOSKINSON, R. M. Active immunisation against steroid hormones for increasing fecundity. In "Immunological Aspects of Reproduction in Mammals" (Ed. D. B. Crighton.), p. 445-474. (Butterworths: London.) 1984.

SMITH, P. O. W. S., HUDSON, N. L., SHAW, L., HEATH, D. A. S., CONDELl, L., PHILLIPS, D. J. \& McNATTY, K. P. Effects of the Booroola gene $(F e c \mathrm{~B})$ on body weight, ovarian development and hormone concentrations during fetal life. J. Reprod. Fertil. 98, p. 41-54, 1993.

THOMAS, G. B., OLDHAM, C. M., MARTIN, G. B. Frequency of luteinizing hormone release in merino ewe with one or two ovulations. In 
“Reproduction in Sheep". (Eds D. R. Lindsay \& D. T. Pearce) p. 102-104 ( Australian Wool Corporation: Camberra), 1984.

TURZILLO, A. M., FORTUNE, J. E. Supression of the secundary FSH surge with bovine follicular fluid is associated with delayed ovarian follicular development in heifers. J. Reprod. Fertil. 89, p. 643-653, 1990.

WALLACE, J. M. \& McNEILY, A. S. Increase in ovulation rate after treatment of ewes with bovine follicular fluid in the luteal phase of the oestrus cycle. J. Reprod. Fertil. 73, p. 505-515, 1985.

WEBB, R., \& ENGLAND, B. G. Identification of the ovulatory follicle in the ewe: associated changes in the follicular size, thecal granulosa cell luteinizing receptors, antral fluid steroids, and circulating hormones during the preovulatory period. Endocrinology. 110, p. 873-881, 1982. 
Tabela 2. Distribuição das ovelhas cobertas e não cobertas durante o período experimental $(\%)$

\begin{tabular}{lccc}
\hline & Controle & Imunizadas & Total \\
\hline Cobertas & $20(33)$ & $22(37)$ & $42(70)$ \\
Não cobertas & $10(17)$ & $8(13)$ & $18(30)$ \\
\hline Total & $30(50)$ & $30(50)$ & $60(100)$ \\
\hline
\end{tabular}

$\chi^{2} P>0,05$

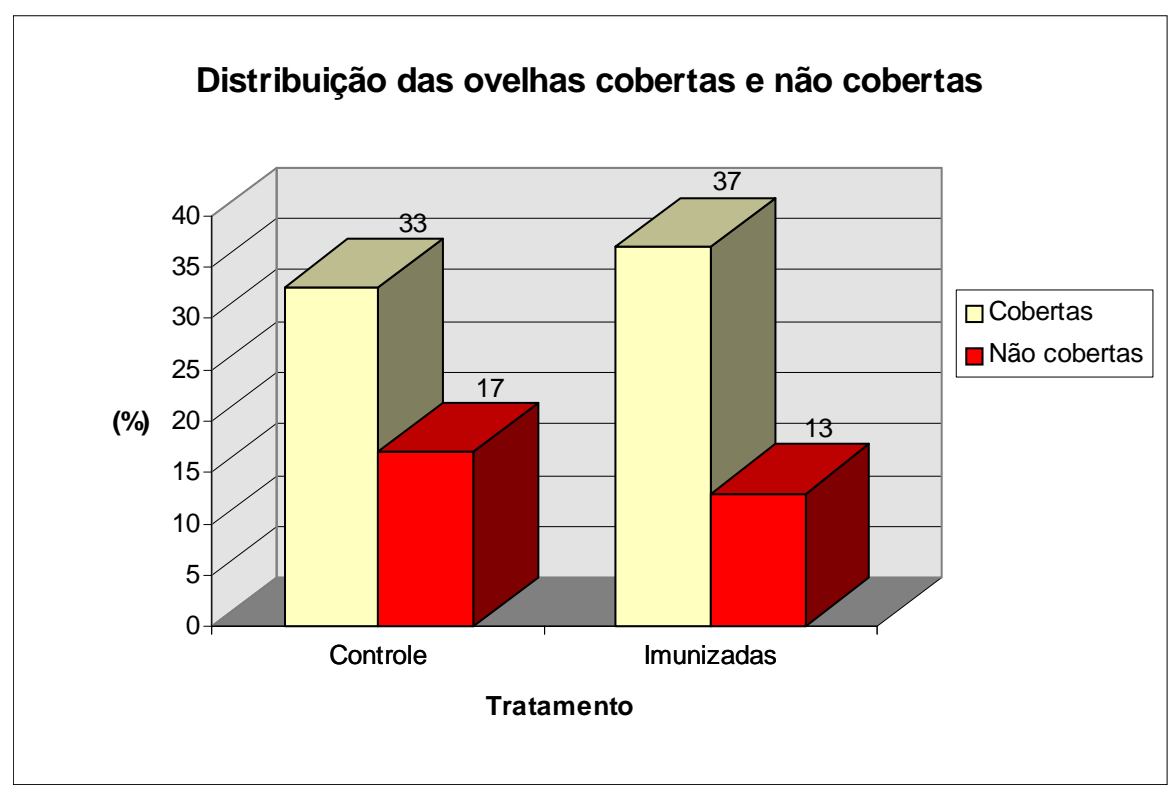


Tabela 3. Número de ovelhas paridas, falhadas e com aborto nos tratamentos (\%)

\begin{tabular}{lccc}
\hline & Controle & Imunizadas & Total \\
\hline Paridas & $14(33)$ & $15(36)$ & $29(69)$ \\
Falhadas & $4(10)$ & $8(19)$ & $12(29)$ \\
Abortos & $1(2)$ & - & $1(2)$ \\
\hline Total & $19(45)$ & $23(55)$ & $42(100)$ \\
\hline$\chi^{2} P>0,05$ & & &
\end{tabular}

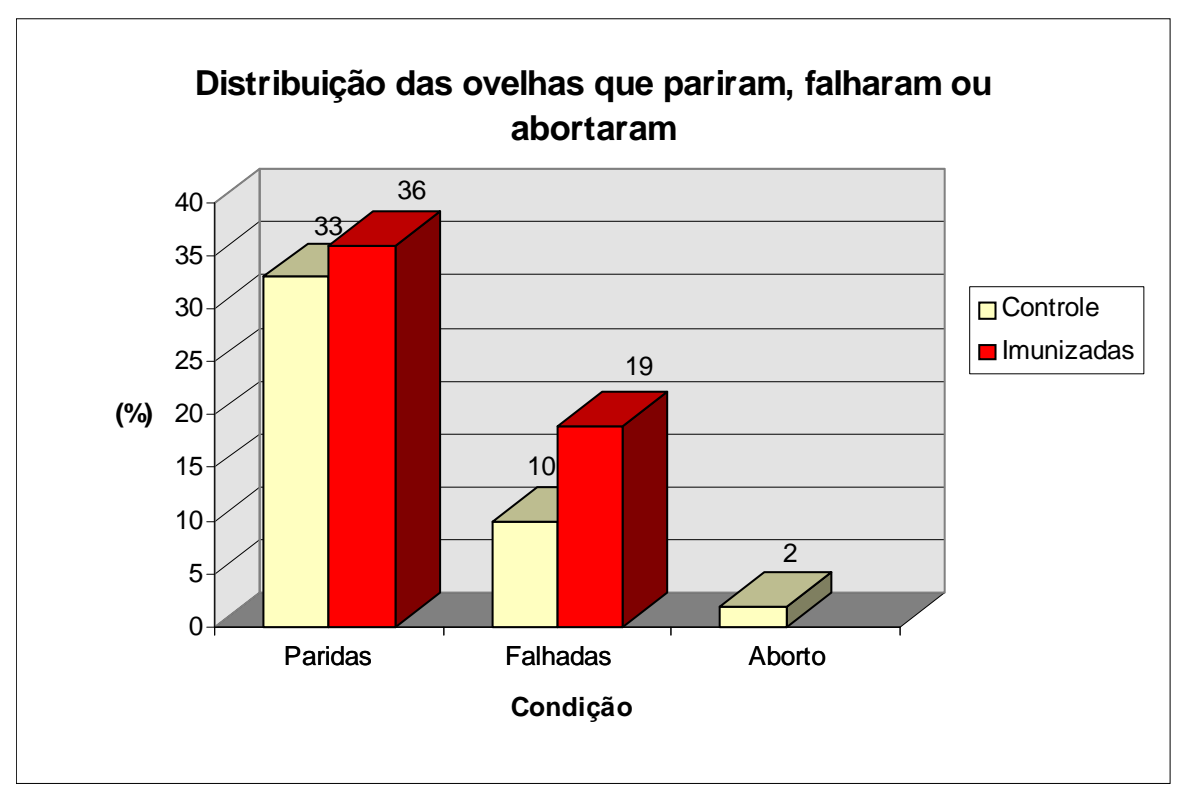


Tabela 4. Fertilidade das ovelhas Ideal e Mestiças expostas à procriação (\%).

\begin{tabular}{lcc}
\hline & Ideal & Mestiças \\
\hline Ovelhas expostas & 30 & 30 \\
Ovelhas paridas & $7(23)$ & $22(73)$ \\
\hline
\end{tabular}

$\chi^{2} P<0,01$

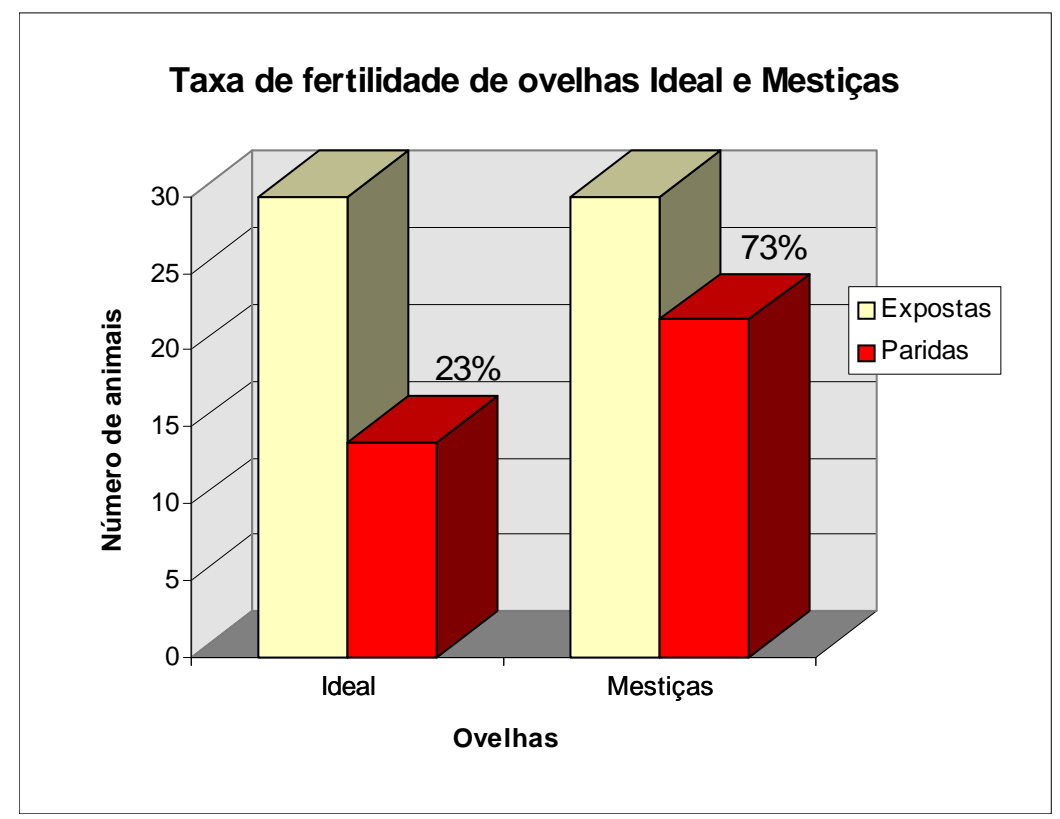


Tabela 5. Número de ovelhas Ideal paridas, falhadas e com aborto nos tratamentos (\%)

\begin{tabular}{lccc}
\hline & Controle & Imunizadas & Total \\
\hline Paridas & $4(29)$ & $3(21)$ & $7(50)$ \\
Falhadas & $2(14)$ & $4(29)$ & $6(43)$ \\
Abortos & $1(7)$ & - & $1(7)$ \\
\hline Total & $7(50)$ & $7(50)$ & $14(100)$ \\
\hline
\end{tabular}

$\chi^{2} P>0,05$

Parições, falhas e abortos das ovelhas Ideal

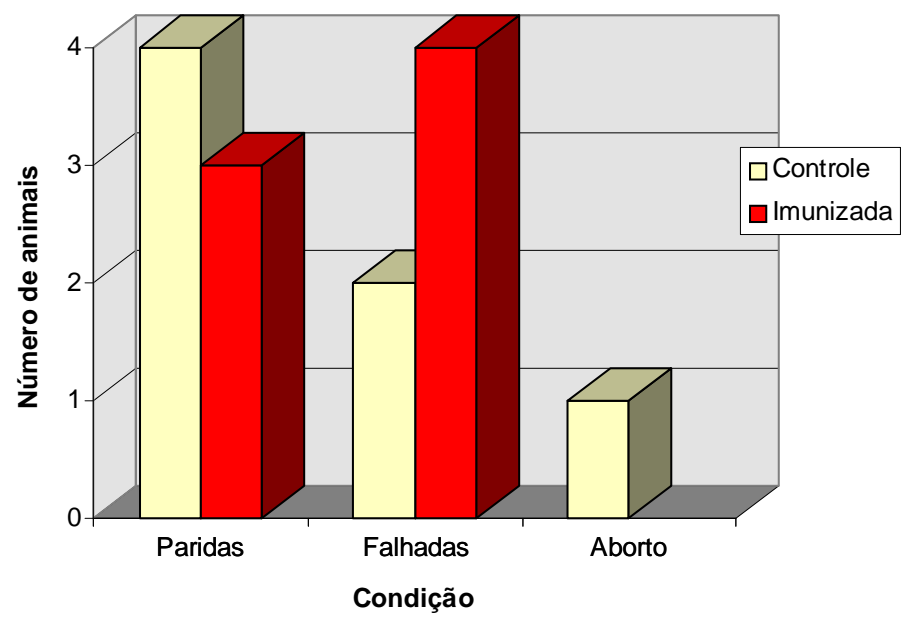


Tabela 6. Número de ovelhas Mestiçasa paridas, falhadas e com aborto nos tratamentos (\%)

\begin{tabular}{lccc}
\hline & Controle & Imunizadas & Total \\
\hline Paridas & $11(39)$ & $11(39)$ & $22(78)$ \\
Falhadas & $2(7)$ & $4(15)$ & $6(22)$ \\
Abortos & - & - & - \\
\hline Total & $13(46)$ & $15(54)$ & $28(100)$
\end{tabular}

$\chi^{2} P>0,05$

Parições, falhas e abortos das ovelhas Mestiças

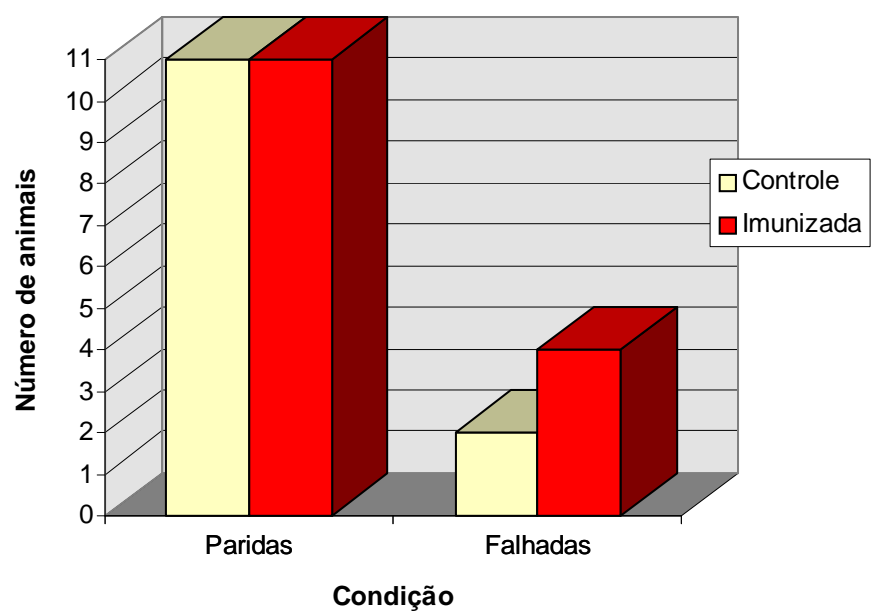


Tabela 7. Resposta das ovelhas aos tratamentos no número e tipo de partos (\%)

\begin{tabular}{lccc}
\hline & Controle & Imunizado & Total \\
\hline Partos simples & $14(48)$ & $10(35)$ & $24(83)$ \\
Partos gemelares & $0(0)$ & $5(17)$ & $5(17)$ \\
Total & $14(48)$ & $15(52)$ & $29(100)$ \\
\hline
\end{tabular}

$\chi^{2} P<0,05$

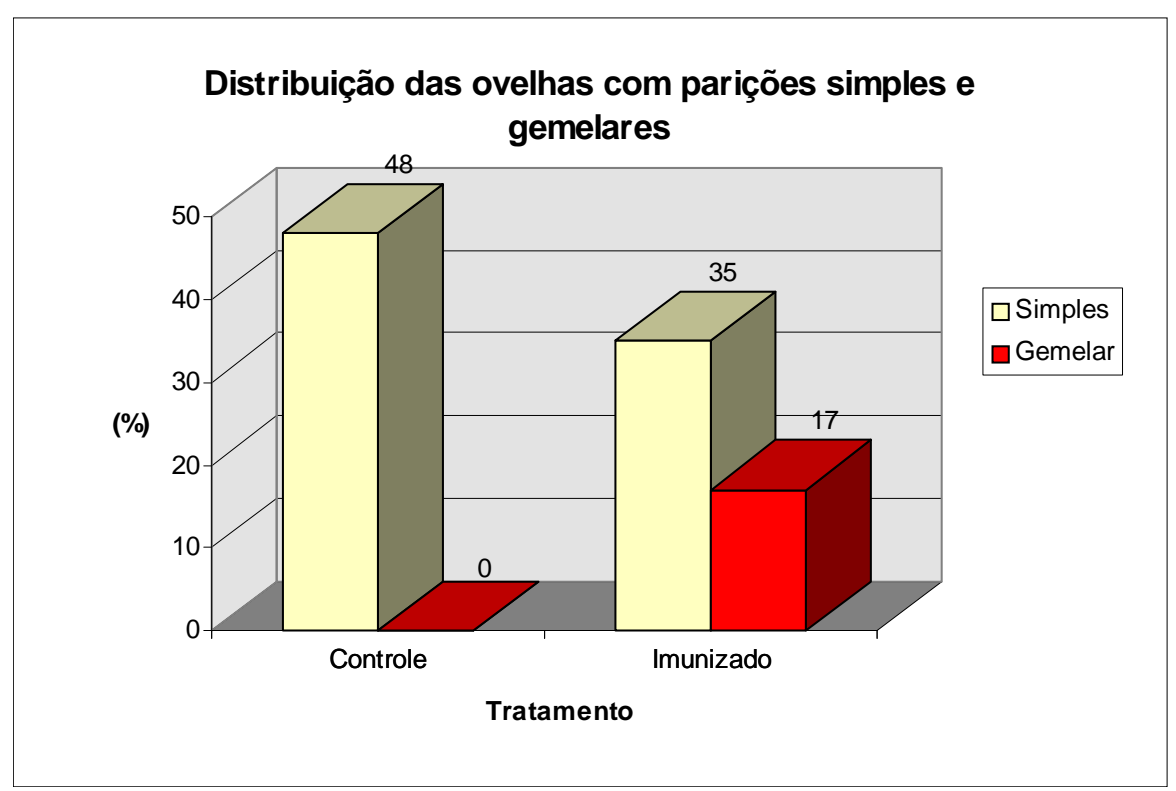


Tabela 8. Resposta das ovelhas Ideal aos tratamentos no número e tipo de partos (\%)

\begin{tabular}{lccc}
\hline & Controle & Imunizado & Total \\
\hline Partos simples & $4(57)$ & $2(29)$ & $6(86)$ \\
Partos gemelares & $0(0)$ & $1(14)$ & $1(14)$ \\
Total & $4(57)$ & $3(43)$ & $7(100)$ \\
\hline
\end{tabular}

$\chi^{2} P>0,05$

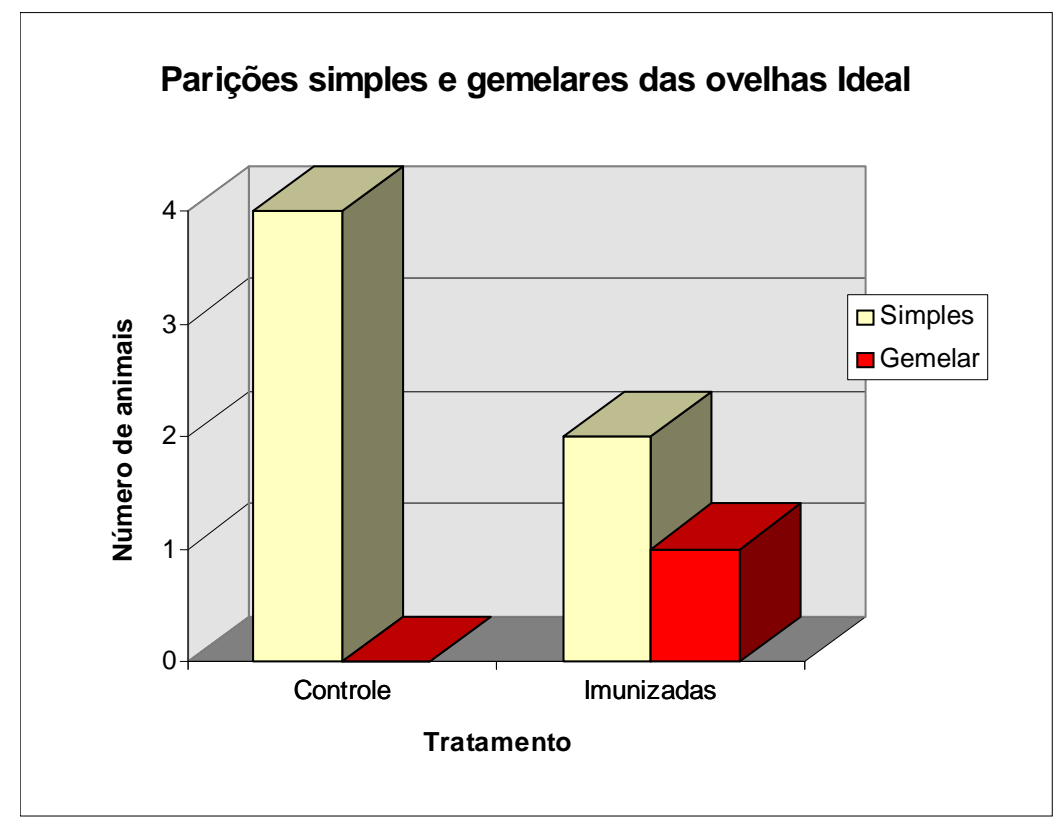


Tabela 9. Resposta das ovelhas Mestiças aos tratamentos no número e tipo de partos (\%)

\begin{tabular}{lccc}
\hline & Controle & Imunizado & Total \\
\hline Partos simples & $11(50)$ & $7(32)$ & $18(86)$ \\
Partos gemelares & $0(0)$ & $4(18)$ & $4(14)$ \\
Total & $11(50)$ & $11(50)$ & $22(100)$ \\
\hline
\end{tabular}

$\chi^{2} P<0,05$

Parições simples e gemelares das ovelhas Mestiças

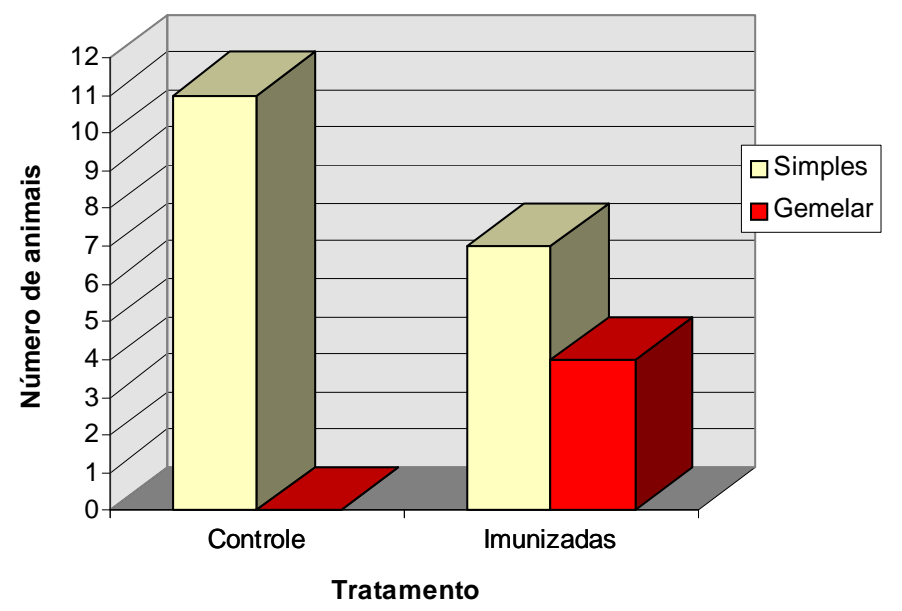


Quadro 1. Estatística descritiva do índice de prolificidade das ovelhas Ideal e Mestiças imunizadas ou não com LFb

\begin{tabular}{ccccc}
\hline Grupo & $\mathrm{N}^{0}$ de partos & $\begin{array}{c}\text { Total } \\
\text { cordeiros }\end{array}$ & Média & Variância \\
\hline Controle & 14 & 14 & 1,0 & 0 \\
Imunizado & 15 & 20 & 1,3 & 0,24 \\
\hline
\end{tabular}

Quadro 2. Análise da variância (ANOVA) do índice de prolificidade das ovelhas Ideal e Mestiças imunizadas ou não com LFb

\begin{tabular}{lccccc}
\hline Fonte de variação & GL & SQ & QM & F & Prob. \\
\hline Tratamentos & 1 & 0,8045 & 0,8046 & 6,5172 & 0,0166 \\
Resíduo & 27 & 3,3333 & 0,1234 & & \\
Total & 28 & 4,1378 & & & \\
\hline
\end{tabular}

